\title{
Antiviral Treatment Reveals a Cooperative Pathogenicity of Baculovirus and Iflavirus in Spodoptera exigua, a Lepidopteran Insect
}

\author{
Miltan Chandra Roy ${ }^{\dagger}$, Shabbir Ahmed ${ }^{\dagger}$, Md. Mahi Imam Mollah, and Yonggyun Kim* \\ Department of Plant Medicals, College of Life Sciences, Andong National University, Andong 36729, Republic of Korea
}

The beet armyworm, Spodoptera exigua, is a serious insect pest infesting various vegetable crops. Two infectious insect viruses, baculovirus and iflavirus, are known to induce epizootics in S. exigua populations. Indeed, some laboratory colonies have appeared to be covertly infected by these viruses. Diagnostic PCR tests detected two different viruses: Spodoptera exigua multiple nucleopolyhedrosis virus (SeMNPV) and iflaviruses (SelfV1 and SelfV2). Viral extract from dead larvae of $S$. exigua could infect $S f 9$ cells and produce occlusion bodies (OBs). Feeding OBs to asymptomatic larvae of $S$. exigua caused significant viral disease. Interestingly, both SelfV1 and SelfV2 increased their titers at late larval stages. Sterilization of laid eggs with $1 \%$ sodium hypochloride significantly reduced SeMNPV titers and increased larval survival rate. Doublestranded RNA (dsRNA) specific to SelfV1 or SelfV2 significantly reduced viral titers and increased larval survival rate. To continuously feed dsRNA, a recombinant Escherichia coli HT115 expressing SelfV1-dsRNA was constructed with an L4440 expression vector. Adding this recombinant $E$. coli to the artificial diet significantly reduced the SelfV1 titer and increased larval survival. These results indicate that laboratory colony collapse of $S$. exigua is induced by multiple viral infections. In addition, either suppression of SeMNPV or SelfV infection significantly increased larval survival, suggesting a cooperative pathogenicity between baculovirus and iflavirus against $S$. exigua.

Keywords: Spodoptera exigua, SeMNPV, iflavirus, dsRNA, viral transmission

Received: December 25, 2020 Accepted: January 18, 2021

First published online: January 22, 2021

*Corresponding author E-mail: hosanna@anu.ac.kr

${ }^{\dagger}$ These authors contributed equally to this work.

Supplementary data for this paper are available on-line only at http://jmb.or.kr.

pISSN 1017-7825 eISSN 1738-8872

Copyright(C) 2021 by The Korean Society for Microbiology and Biotechnology

\section{Introduction}

Baculoviruses are known to produce occlusion bodies (OBs) including rod-shaped nucleocapsids (virions). They are divided into nucleopolyhedroviruses (NPVs) and granuloviruses (GVs) [1]. NPVs have multiple virions within each OB, whereas GVs usually contain a single virion in a granular OB form. These OBs are made of genetically related polyhedrin or granulin proteins that are not related to other occlusion proteins of entomopoxviruses or cypoviruses. Each virion of NPVs may envelope single or multiple nucleocapsids (traditionally called SNPV or MNPV, respectively). However, these baculoviruses are classified based on the order of their host insects, including alphabaculoviruses (lepidopteran NPVs), betabaculoviruses (lepidopteran GVs), gammabaculoviruses (hymenopteran NPVs), and deltabaculoviruses (dipteran NPVs) [2]. Alphabaculoviruses are divided into Group I and Group II depending on the nature of a fusion protein (GP64 for Group I versus F protein for Group II) required for the entry of enveloped viruses into host cells [3].

Baculovirus genomes are double-stranded, circular, supercoiled DNAs with sizes ranging from $82 \mathrm{~kb}$ (Neodiprion lecontei NPV) to $179 \mathrm{~kb}$ (Xestia c-nigrum GV) [4]. Despite such genome size variation, only 31 genes appear to be common to all baculoviruses, including viral structural proteins, DNA polymerase, transcriptional factors, and alpha-amanitin-resistant RNA polymerase (Rohrmann, 2008). The large number of non-overlapping genes suggests that baculoviruses have co-evolved with their hosts and diverged genetically during evolution [5].

Baculoviruses produce two structurally distinct forms of virus particle: budded virus (BV) and occlusionderived virus (ODV). BV and ODV are identical in their genomes. Although they have similar nucleocapsids, they have different envelope proteins and lipid contents. BV is produced when nucleocapsids bud off from infected cells. It then acquires a lipoprotein envelope containing a virus-encoded fusion protein of GP64 or F. In contrast, ODV is produced in the nucleus of infected cells. It contains specific envelope components including five per os infectivity factors [6].

The beet armyworm, Spodoptera exigua (Hübner) (Lepidoptera: Noctuidae), is highly polyphagous. It is considered to be one of the most devastating pests, infesting over 80 crop species grown in fields and greenhouses worldwide and having significant economic impacts [7]. Due to rapid development of resistance to multiple agents and ecological effects of excessive dependence on chemical insecticides for controlling this pest [8], NPV has been widely acknowledged as an environmentally friendly alternative to chemical insecticides [9]. NPV- 
infected larvae always exhibit no feeding behavior, pale body color, and swelling, resulting in death.

S. exigua multiple nucleopolyhedrovirus (SeMNPV) has been successfully applied as a large-scale commercial biological insecticide against S. exigua [10]. SeMNPV is a Group II alphabaculovirus with a $128 \mathrm{~kb}$ dsDNA genome and 127 putative open reading frames (ORFs) forming a nucleocapsid with proteins [11]. One to seven viral particles are enveloped in a polyhedron $(\sim 1.4 \mu \mathrm{m})$ that exhibits high host specificity. SeMNPV infects the larvae of S. exigua, but not those of other closely related lepidopteran species [11].

Iflavirus (IfV) is a group of single-stranded RNA viruses infecting arthropods. These viruses belong to the order Picornavirales [12]. Two iflaviruses (SeIfV1 and SeIfV2) are known in S. exigua. They can form icosahedral capsids of $27 \mathrm{~nm}$ in diameter. The genome size is 10.3 nucleotides for SeIfV1 and 9.4 nucleotides for SeIfV2. Their genomes have a single ORF to be translated as a single polypeptide that is subsequently cleaved into functional and structural proteins $[13,14]$. Although some IfVs can cause clear infection signs (e.g., those infecting Bombyx mori [15] and Apis mellifera [16]), most IfV infections are asymptomatic [17]. To enhance viral pathogenicity, IfV has been treated with baculoviruses in a mixture [18]. In fact, $S$. exigua collected in the field could be infected with both SeMNPV and two iflaviruses [19]. OBs of SeMNPV produced in insects infected by both viruses contain IfV genomes [20]. Overt infection of SeIfV s can potentiate the viral pathogenicity of SeMNPV [21].

Viruses can cause devastating epizootics of disease in insect colonies. Thus, continuous monitoring and disinfection processes are needed to maintain colony health $[22,23]$. IfVs are rapidly transmitted and can reach a high prevalence of infection in natural populations and laboratory insect colonies [24]. Recent laboratory colony collapses in various places in Korea suggest that $S$. exigua colonies might be infected with SeMNPV and SeIfVs. This study confirmed infections by both SeMNPV and SeIfVs in S. exigua and showed their cooperative pathogenicity to $S$. exigua using antiviral treatments.

\section{Materials and Methods \\ Rearing S. exigua}

Larvae of S. exigua used in this study originated from a welsh onion (Allium fistulsum L.) field in Andong, Korea and were reared for 25 years in a laboratory at $25 \pm 2^{\circ} \mathrm{C}$ with a $16: 8 \mathrm{~h}$ light/dark cycle and relative humidity of $60 \pm$ 5\%. The larvae were fed an artificial diet and underwent five instars (L1-L5) [25]. Adults were supplied with a 10\% sucrose solution. Occasionally, field populations were introduced to the laboratory colony to prevent random genetic drift.

\section{PCR Diagnosis of SeMNPV, SeIfV1, and SeIfV2}

For diagnosis of SeMNPV contamination, genomic DNA (gDNA) was extracted from S. exigua larvae using 5\% Chelex (Bio-Rad, USA). For diagnosis of SeIfVs, RNA samples were extracted from the whole body or different tissues (hemocytes, fat body, midgut, and epidermis) of L5 larvae of S. exigua using Trizol reagent (Invitrogen, USA) according to the manufacturer's instructions. Extracted RNA was resuspended in nuclease-free water and quantified using a spectrophotometer (NanoDrop, Thermo Scientific, USA). RNA ( $1 \mu \mathrm{g}$ ) was used for cDNA synthesis with an RT PreMix (Intron Biotechnology, Korea) containing oligo dT primer according to the manufacturer's instructions. PCR was conducted using DNA Taq polymerase (GeneALL, Korea) with genespecific primers (Table S1). After heat treatment at $94^{\circ} \mathrm{C}$ for $5 \mathrm{~min}$, PCR was performed with 40 temperature cycles of $94^{\circ} \mathrm{C}$ for $1 \mathrm{~min}, 52^{\circ} \mathrm{C}$ for $1 \mathrm{~min}$, and $72^{\circ} \mathrm{C}$ for $1 \mathrm{~min}$. A ribosomal protein, $R L 32$, was used as a reference gene to confirm cDNA preparation.

Quantitative PCR (qPCR) to Monitor SeMNPV, SeIfV1, and SeIfV2 Titers During S. exigua Development

qPCR was performed to quantify mRNAs of IfV and SeMNPV using a real-time PCR machine (StepOnePlus Real-Time PCR System, Applied Biosystems, Singapore) with Power SYBR Green PCR Master Mix (Life Technologies, USA) according to the guidelines of Bustin et al. [26]. For SeIfV1 and SeIfV2, RNA samples were extracted from different developmental stages (100 eggs, 20 young larvae (L1-L3), three L4 larvae, one L5 larva, one pupa, and one adult) using Trizol reagent. Extracted RNAs were dissolved in $50 \mu \mathrm{l}$ of diethyl pyrocarbonatetreated deionized and distilled water. Their concentrations were quantified with a spectrophotometer. cDNAs were synthesized using $1 \mu \mathrm{g}$ of total RNA and Maxime RT PreMix (Intron Biotechnology). Synthesized cDNAs were used as templates for $\mathrm{qPCR}$ amplification. The reaction mixture $(20 \mu \mathrm{l})$ contained $10 \mu \mathrm{l}$ of Power SYBR Green PCR Master Mix, $3 \mu \mathrm{l}$ of cDNA template (50 ng), $1 \mu \mathrm{l}$ each of forward and reverse primers (Table S1), and $5 \mu \mathrm{l}$ of sterile water. In case of SeMNPV, gDNA (50 ng) was used as template. qPCR cycling began with heat treatment at $95^{\circ} \mathrm{C}$ for $10 \mathrm{~min}$ followed by 40 cycles of denaturation at $94^{\circ} \mathrm{C}$ for $30 \mathrm{~s}$, annealing at $52^{\circ} \mathrm{C}$ for $30 \mathrm{~s}$, and extension at $72^{\circ} \mathrm{C}$ for $30 \mathrm{~s}$. The expression level of a ribosomal protein gene, $R L 32$, was used as a reference to normalize target gene expression levels after different treatments. PCR specificity was assessed by melting curve analysis. Quantitative analysis was performed using the comparative CT $\left(2^{-\Delta \Delta \mathrm{CT}}\right)$ method [27].

\section{SeMNPV Isolation and Infection of Sf9 Cells}

Baculovirus was isolated from infected larvae followed the method of Choi et al. [28]. Briefly, 25 infected L5 larvae of $S$. exigua were taken into a $50 \mathrm{ml}$ tube containing $10 \mathrm{ml}$ sterilized water and macerated using a sterilized pestle. The sample was then filtered through five layers of cheese cloth before being centrifuged at $4,000 \times g$ for $5 \mathrm{~min}$. The supernatant was transferred to a new tube, filtered through a $0.22 \mu \mathrm{m}$ filter (Acrodisc, Pall Corporation, USA), and used for subsequent bioassay. The Sf9 cell line (IPLB-Sf21-AE) was derived from Spodoptera frugiperda pupal ovarian tissue. Sf9 cells were infected with the filtrate at a ratio of $1 \mathrm{ml}$ of filtrate in $5 \mathrm{ml}$ of confluent culture. After $24 \mathrm{~h}$ of incubation at $28^{\circ} \mathrm{C}$, the culture medium was replaced with fresh TC-100 
cell culture medium (Welgene, Korea) containing $5 \%$ fetal bovine serum (FBS, Welgene) and cultured for another $48 \mathrm{~h}$. Then the media containing cells were centrifuged at 1,000 $\times g$ for $3 \mathrm{~min}$. The supernatant was collected into a $15 \mathrm{ml}$ fresh tube and used for bioassay subsequently.

\section{Plaque Assay to Quantify SeMNPV}

Viral titer was determined by plaque assays. Briefly, one day before the assay, Sf9 cells were plated in 6-well plates at a density of $80 \%$. The virus was serially diluted up to $10^{-5}$ to $10^{-10}$ with the cell culture medium. Cells were infected with $200 \mu$ l of each virus dilution by adding it to the culture medium and evenly distributed it over the monolayer of cells. The virus was allowed to infect the cells by incubation at $37^{\circ} \mathrm{C}$ for $60 \mathrm{~min}$. During this time, an agarose overlay medium was prepared by melting $5 \mathrm{ml}$ of $5 \%$ agarose and cooling down to $44^{\circ} \mathrm{C}$. Then $50 \mathrm{ml}$ of a warm $\left(44^{\circ} \mathrm{C}\right)$ cell culture medium was added to the agarose. The virus-containing medium was removed from cells and replaced with the agarose solution. Plaques were observed after 7 days of incubation at $28^{\circ} \mathrm{C}$. Observation of plaques was done by adding $1 \mathrm{ml}$ of neutral red solution ( $0.03 \%$ in PBS) to each well followed by incubation at $37^{\circ} \mathrm{C}$ for $3 \mathrm{~h}$.

RNA interference (RNAi) against SeIfV 1 and SeIfV2

RNAi was performed using double-stranded RNAs (dsRNAs) specific to SeIfV1 and SeIfV2, respectively. These dsRNAs were prepared using a MEGAscript RNAi Kit (Ambion, USA) according to the manufacturer's instructions. DNA fragments were obtained by PCR using virus-specific primers (Table S1) containing T7 promoter sequence at the $5^{\prime}$ end. Sense and antisense RNA strands were synthesized using T7 RNA polymerase at $37^{\circ} \mathrm{C}$ for $4 \mathrm{~h}$. The resulting dsRNA was mixed with transfection reagent Metafectene PRO (Biontex, Germany) at $1: 1(\mathrm{v} / \mathrm{v})$ ratio and then incubated at $25^{\circ} \mathrm{C}$ for $30 \mathrm{~min}$ to form liposomes. Then, $1 \mu \mathrm{g}$ of dsRNA was injected into the hemocoel of apparently healthy L5 larvae using a microsyringe (Hamilton, USA) equipped with a 26-gauge needle. At $12 \mathrm{~h}$ post injection, RNAi efficacy was determined by reverse transcription (RT)-qPCR as described above. A green fluorescence protein (GFP) gene was used as a control dsRNA (dsCON) [29]. Each treatment was replicated three times using independent RNA preparations.

\section{Construction of Recombinant Escherichia coli Expressing dsRNA Specific to SeIfV1}

To clone a partial genomic fraction (188 bp) of SeIfV 1, L4440 plasmid containing multiple cloning sites flanked by two T7 promoters in an inverted orientation was used. Restriction sites of HindIII and XbaI were chosen for cloning because these sites were not present in SeIfV1 based on analysis using the Gene-Quest program (DNASTAR, USA). This recombinant L4440 vector containing SeIfV1 was then transformed into E. coli HT115 (DE3) competent cells lacking RNase III by electroporation.

\section{Overexpression of dsRNA in Transformed E. coli and Quantification}

To produce dsRNA, a single colony of transformed bacteria was cultured in Luria-Bertani (LB) containing $100 \mu \mathrm{g} / \mathrm{ml}$ ampicillin at $37^{\circ} \mathrm{C}$ with shaking at $250 \mathrm{rpm}$ for $16 \mathrm{~h}$. The culture broth $(5 \mathrm{ml})$ was added to $500 \mathrm{ml}$ of fresh $\mathrm{LB}$ medium containing $100 \mu \mathrm{g} / \mathrm{ml}$ ampicillin and allowed to grow at $37^{\circ} \mathrm{C}$ until it reached an exponential bacterial growth phase with absorbance of $0.6 \sim 0.7$ at $600 \mathrm{~nm}$. Expression of T7 polymerase was induced by adding $0.4 \mathrm{mM}$ (final concentration) of isopropyl thiogalactose (IPTG) and then further cultured at $30^{\circ} \mathrm{C}$ for $6 \mathrm{~h}$. Total bacterial RNA was extracted with an RNA Extraction Mini Kit (Qiagen Korea, Seoul, Korea). The dsRNA was confirmed by $1 \%$ agarose gel electrophoresis. For bioassays, IPTG-induced recombinant bacterial culture was centrifuged at 7,000 $\times g$ for $10 \mathrm{~min}$. The resulting bacterial cell pellet was resuspended in distilled water. The bacterial suspension was then treated at $95^{\circ} \mathrm{C}$ for $10 \mathrm{~min}$. Subsequently, the bacterial suspension was subjected to ultrasonication at $100 \%$ intensity for 3 cycles ( 5 second per cycle) with an ultrasonicator (Bandelin Sonoplus, Germany). Quantification of dsRNA amounts produced by recombinant bacteria followed the method described by Kim et al. [30].

\section{Feeding Bioassay Using dsRNA-Expressing Recombinant Bacteria}

Recombinant bacteria $\left(10 \mu \mathrm{l}, 7 \times 10^{9} \mathrm{cells} / \mathrm{ml}\right)$ were mixed with $50 \mathrm{mg}$ of larval artificial diet. This treated diet was used to feed 30 larvae at early L1. Every $48 \mathrm{~h}$, the diet was replaced with a freshly treated diet. As a control, nonrecombinant HT115 bacteria were used to treat the diet. Each treatment was replicated three times. For each replication, 30 larvae were used. Survival rates were estimated for each developmental stage from L1 larvae to adults.

\section{Egg Sterilization Using Sodium Hypochlorite ( $\mathrm{NaOCl})$}

$\mathrm{NaOCl}$ solution was purchased from Yakuri Pure Chemicals (Japan). Different concentrations $(0.1 \%, 0.5 \%$, and $1 \%$ ) of $\mathrm{NaOCl}$ were used to treat S. exigua eggs by diluting a stock solution of $12 \% \mathrm{NaOCl}$ with sterilized deionized water. Eggs were incubated in $\mathrm{NaOCl}$ for $5 \mathrm{~min}$ and then rinsed with sterile water for $2 \mathrm{~min}$. Treated eggs were dried for $30 \mathrm{~min}$ on a clean bench. To examine the effect of immersion time on SeMNPV titer and survival, eggs were also treated with $1 \% \mathrm{NaOCl}$ for $5 \mathrm{~min}, 10 \mathrm{~min}$, and $20 \mathrm{~min}$ followed by a $2 \mathrm{~min}$ water rinse. Each treatment was replicated three times (30 eggs for each replication).

\section{Statistical Analysis}

Data from all assays were analyzed by one-way Analysis of Variance (ANOVA) of PROC GLM for continuous variables using SAS program [31]. All studies were plotted by mean \pm standard error using Sigma plot. Means were 
A

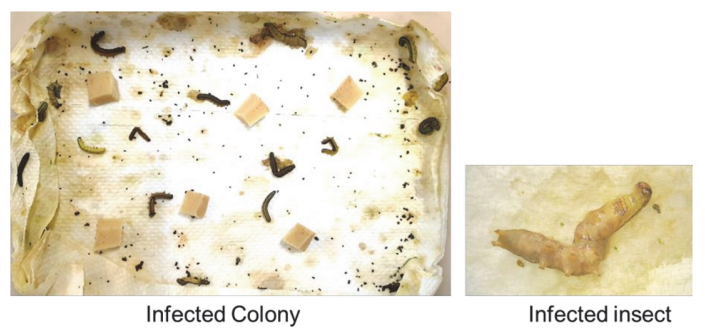

B

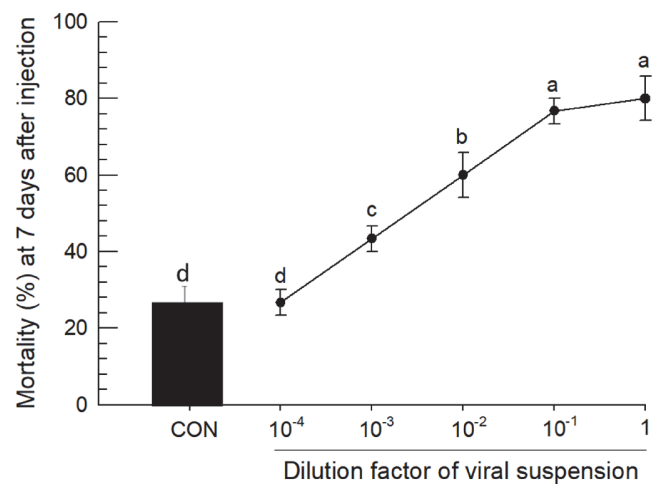

Fig. 1. Colony collapse of S. exigua with viral symptoms. (A) Colony collapse symptom of S. exigua larvae showing flacherie symptoms. (B) Mortality of S. exigua larvae at 7 days after injection of SeMNPV viral extract. Viral particles were extracted from 25 infected fifth instar larvae and $2 \mu \mathrm{l}$ of the extract was injected into healthy L5 larvae. Each dose was replicated three times (ten larvae for each replication). Different letters above standard error bars indicate significant difference among means of each species at Type I error $=0.05$ (LSD test).

compared by a least squared difference (LSD) and discriminated at Type I error $=0.05$. The significance of difference between the two groups was analyzed using Student's $t$-test of Sigma plot software 12.0 version. $p$-value $<0.05$ was considered to be statistically significant for Student's $t$-test.

\section{Results}

Colony Collapse with Viral Infection Symptoms

A laboratory colony has been maintained for the last 25 years with an artificial diet described in Materials and Methods. Its population size varied depending on the handling techniques of researchers. Recently, the laboratory population suddenly died, mostly at the late larval stage, with virus infection-like symptoms (Fig. 1A). The dead larval bodies were melted (wilted) and had released hemolymph. These larvae were collected and used to isolate viral particles by filtration and centrifugation. The pellet was resuspended in sterilized water and used for injection to non-symptomatic larvae. Treated larvae exhibited the same viral infection-like symptoms. The viral extract killed the larvae in a dose-dependent manner depending on the dilution factor (Fig. 1B).

\section{Detection of Viral Pathogens Using PCR Diagnosis}

In other laboratory colonies, S. exigua has been reported to show covert infection with baculovirus and iflaviruses [32]. We tested our laboratory colony with three diagnostic primers specific for SeMNPV and two IfV species. Results of PCR diagnosis showed that our laboratory colony was infected with SeMNPV, SeIfV1, and

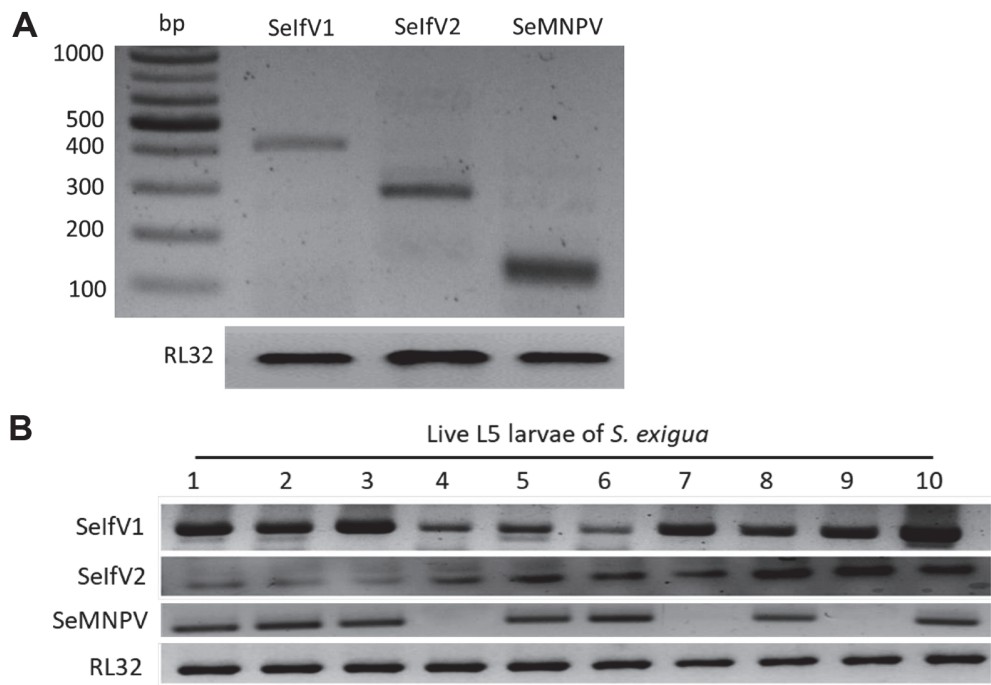

Fig. 2. Detection of viral pathogens using PCR diagnosis. (A) SeMNPV and SeIfVs were detected using gene-specific primers (Table S1). (B) Infectivity assessment of SeMNPV and SeIfVs using randomly selected ten L5 larvae of a laboratory colony. A ribosomal protein, $R L 32$, was used to validate cDNA integrity. PCR products were separated on agarose (1\%) gel. 
A

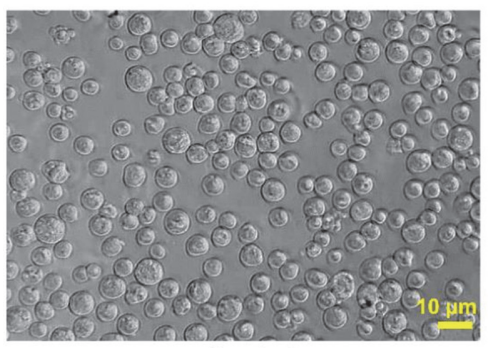

Control

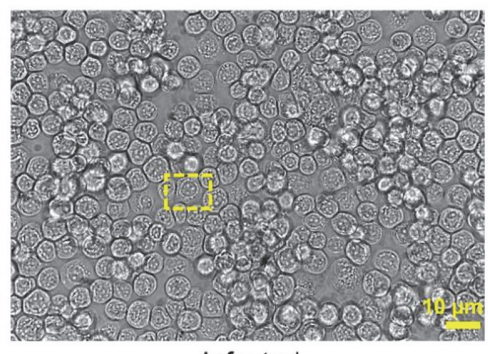

Infected

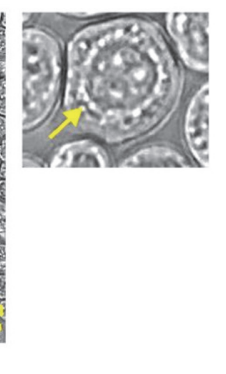

B

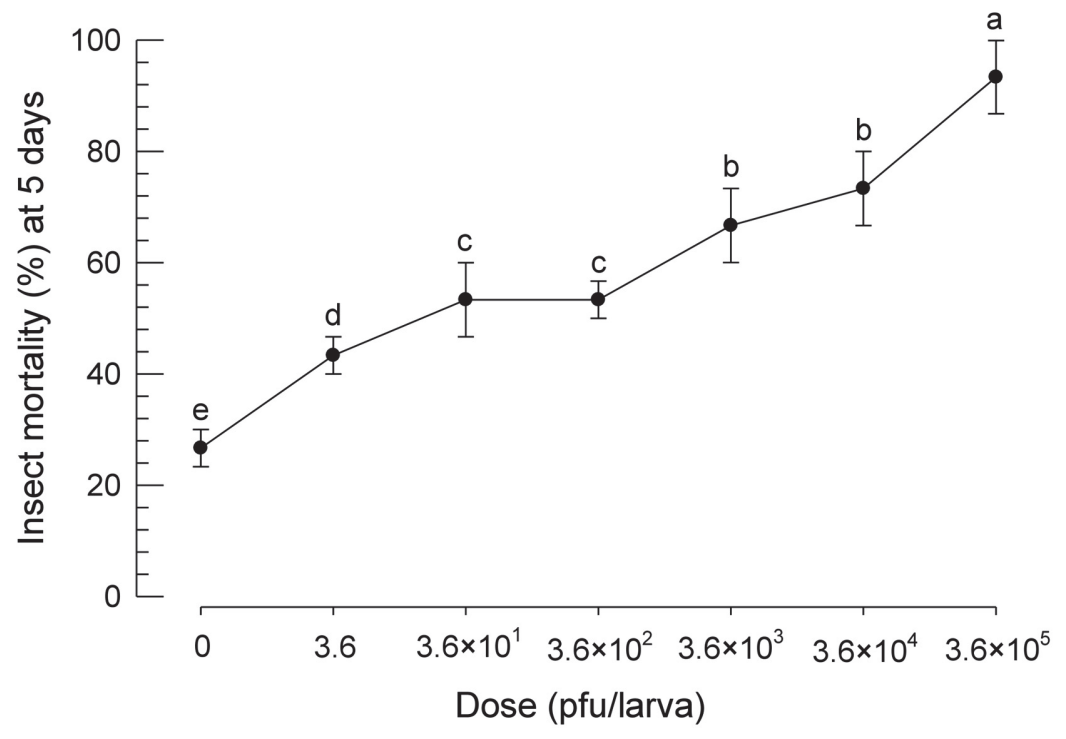

Fig. 3. Polyhedral formation of a viral isolate in Sf9 cells and its infectivity in S. exigua. (A) Polyhedra (see a magnified square) in Sf9 cells infected with a viral isolation from larvae exhibiting a virus infection-like symptom. In contrast, non-infected Sf9 cells did not show any polyhedral in their cytoplasm. (B) Pathogenicity of budded viruses (BVs) quantified with plaque assays. BV suspension was injected into L5 larvae (1 $\mu$ l per larva). Mortality was assessed at $24 \mathrm{~h}$ after injection and daily thereafter for up to 5 days. Each BV dose was replicated three times (ten larvae for each replication). Different letters above standard error bars indicate significant difference among means of each species at Type I error $=0.05$ (LSD test).

SeIfV2 (Fig. 2A). Since L5 larvae showed most viral infection symptoms, they were randomly selected for PCR diagnosis (Fig. 2B). All larvae were infected by two SeIfV viruses, while not all larvae were infected by SeMNPV.

\section{SeMNPV Isolation and Infectivity}

To observe the OB particles of SeMNPV, Sf9 cells were infected with viral extract (Fig. 3A). At 3 days postinfection, infected Sf9 cells formed viral particles. The cultured medium presumably containing the BV form of the SeMNPV was quantified with a plaque assay and injected into larvae (Fig. 3B). SeMNPV caused mortality of S. exigua in a dose-dependent manner.

\section{Viral Replication of SeIfV1 and SeIfV2}

Two iflaviruses were relatively titrated in the laboratory population of S. exigua with qPCR (Fig. 4). Both IfVs were detected in all developmental stages, with late larval stages exhibiting relatively high viral levels (L3-L5 stages for SeIfV1 and L4-L5 stages for SeIfV2) (Fig. 4A) presumably due to viral replication. In L5 larvae, both IfVs were highly detected in the midgut and fat body (Fig. 4B).

\section{Egg Sterilization and SeMNPV Viral Titers}

Sodium hypochloride $(\mathrm{NaOCl})$ was used to sterilize viral contamination [33]. Egg sterilization with $\mathrm{NaOCl}$ suppressed SeMNPV viral titers in all developmental stages (Fig. 5A). However, $\mathrm{NaOCl}$ treatment did not suppress IfV titers. An increase of $\mathrm{NaOCl}$ concentration was effective in suppressing SeMNPV level and increasing larval survival rate (Fig. $5 \mathrm{~B}$ ). Five minutes of incubation time with $1 \% \mathrm{NaOCl}$ was optimal for SeMNPV sterilization (Fig. 5C). 

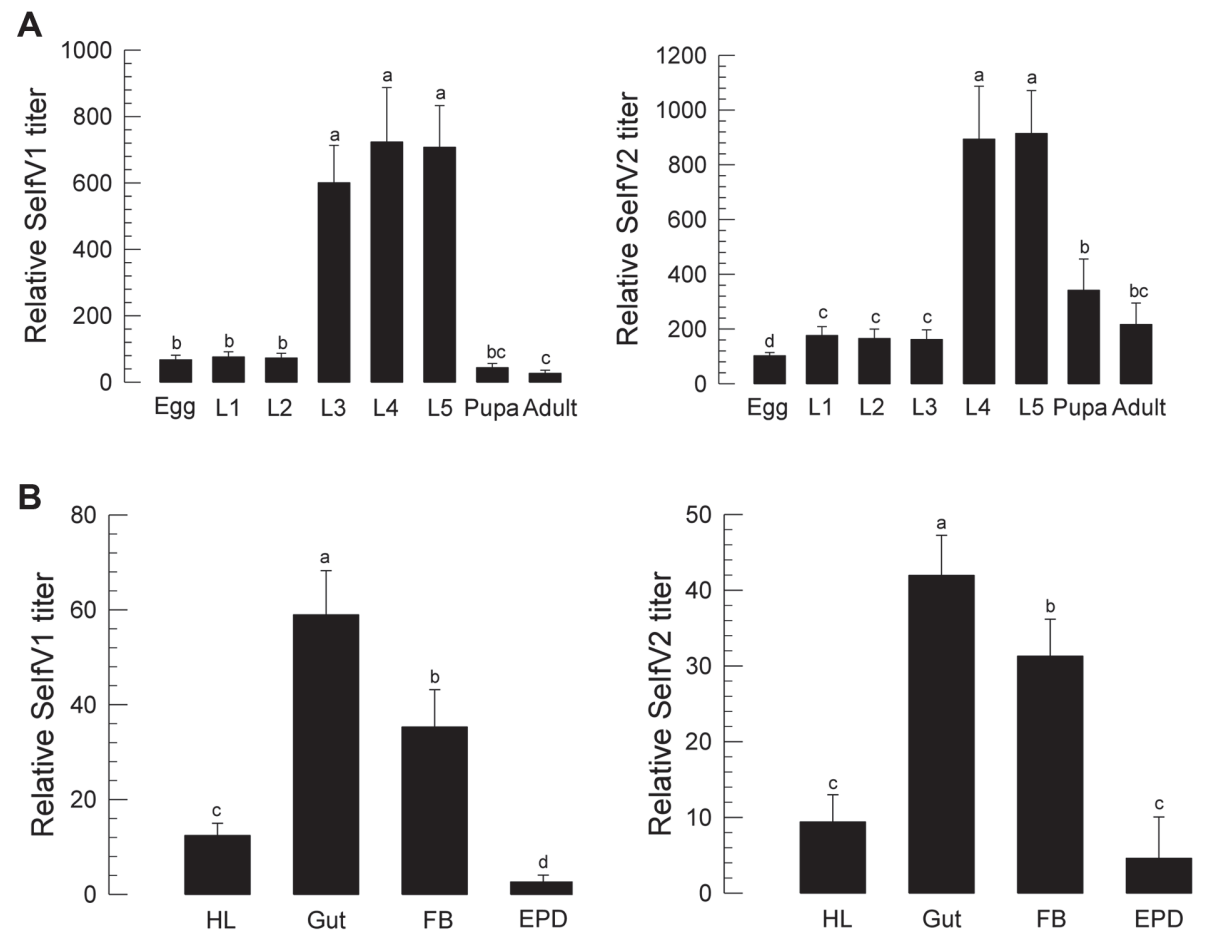

Fig. 4. Viral replication of SeIfV1 and SeIfV2 in different developmental stages and tissues of S. exigua. Viral titers of SeIfV1 and SeIfV2 were quantified by RT-qPCR. (A) Different developmental stages of egg, 1st to $4^{\text {th }}$ instar ('L1-L4'), pupa, and adult. (B) Different tissues in L5 larvae: midgut ('Gut'), fat body ('FB'), epidermis ('EPD'), and hemolymph ('HL'). Different letters above standard error bars indicate a significant difference among means at Type I error $=0.05$ (LSD test).

\section{RNAi Treatment against SeIfV1 and SeIfV2}

To suppress IfV titers, dsRNA was generated using an in vitro transcription kit. These specific dsRNAs were effective in suppressing SeIfV1 levels for $48 \mathrm{~h}$ post-injection (Fig. 6A). However, the SeIfV2 levels were suppressed for only for $24 \mathrm{~h}$ and returned to control level at $48 \mathrm{~h}$. The dsRNA treatment significantly $(p$-value $<0.05)$ rescued larvae from the viral disease (Fig. 6B). Interestingly, treatment with the mixture was highly effective in rescuing larvae from viral disease.

Construction of Recombinant E. coli Expressing dsRNA Specific to SeIfV1 and its Administration to Larvae

Oral administration of dsRNA was effective in suppressing target genes in S. exigua [30]. To persistently suppress IfV levels, a recombinant $E$. coli expressing dsRNA specific to SeIfV1 was constructed (Fig. 7A). Addition of IPTG inducer to the bacterial culture markedly enhanced dsRNA (Fig. 7B). Induced E. coli was harvested and their bacterial cell walls were destabilized by ultrasonication to facilitate dsRNA release after ingestion of bacteria [30]. An artificial diet containing $1 \%$ recombinant bacteria was fed to larvae from hatch to pupation (Fig. 7C). The RNA level of SeIfV1 was highly suppressed at larval, pupal, and adult stages. Larvae fed with the recombinant E. coli showed significantly increased pupation rate (Fig. 7D).

\section{Discussion}

Insects are attacked by a wide range of viruses. Covert infections are increasingly shown to be common in field populations of Lepidoptera [34]. Here, we reported a laboratory colony collapse of S. exigua due to multiple viral infections leading to an epizootic. A colony of S. exigua had been maintained in a laboratory for over 25 years but recently exhibited viral infection symptoms. It was found that these larvae were infected by SeMNPV and SeIfV based on PCR diagnosis using the technique developed by Virto et al. [32]. Indeed, the Spanish group reported that $54 \%$ of the field population are infected by SeMNPV, among which $8.4 \%$ of individuals are also infected by SeIfV [32]. In contrast, almost all larvae in our laboratory population were infected by both viral species. Such covert infection with viruses might have been caused by occasional introduction of field populations to maintain the laboratory population. Quantification of SeMNPV viral titers in asymptomatic individuals over two laboratory generations showed a wide range (from $0.29 \mathrm{pg}$ per larva to $3.5 \times 10^{5} \mathrm{pg}$ per larva), which resulted in a differential susceptibility to SeMNPV superinfections [35]. These results suggest transmission patterns of baculovirus in the environment and the role of covert infections in host-pathogen interaction dynamics. In Spain, two SeIfV strains (SeIfV1 and SeIfV2) have been reported in wild populations and laboratory colonies of S. exigua [36].

Covert infection of SeMNPV is not uncommon. It usually causes spontaneous disease outbreaks. SeMNPV exhibits an oral infection via the peritrophic matrix (PM) and causes midgut cells to invade the hemocoel of 

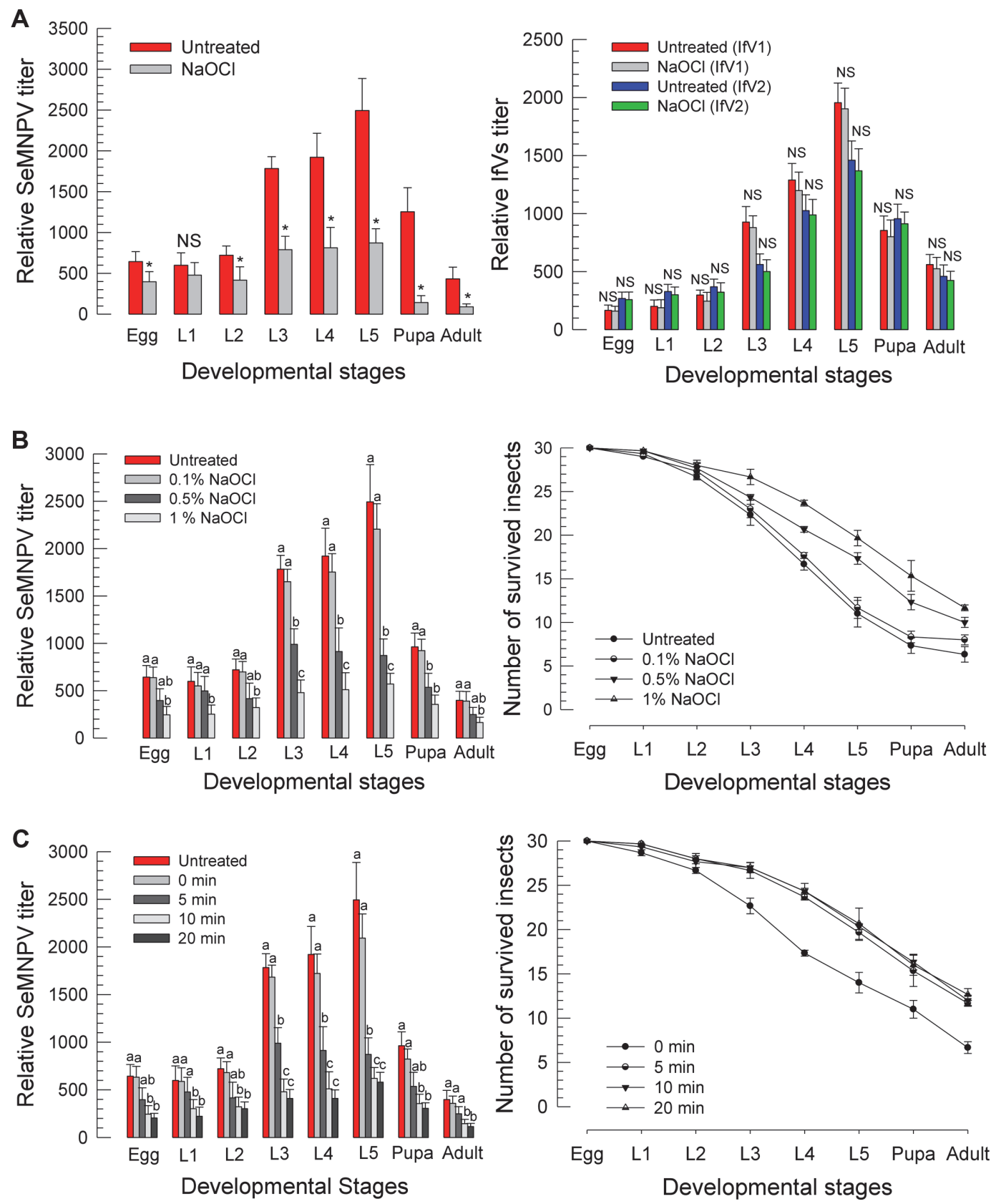

Fig. 5. Effects of egg sterilization using $\mathrm{NaOCl}$ on SeMNPV and SeIfV titers in different developmental stages of S. exigua. (A) RT-qPCR quantification of SeMNPV and SeIfV titers. Eggs were sterilized with $0.5 \% \mathrm{NaOCl}$ for five minutes. (B) RT-qPCR quantification of SeMNPV titers. Eggs were sterilized with $0.1,0.5$, and $1 \% \mathrm{NaOCl}$ for 5 min. (C) Quantification of SeMNPV titers after sterilizing eggs with $1 \% \mathrm{NaOCl}$ for 0, 5, 10, $20 \mathrm{~min}$ and the survivorship of S. exigua. Different letters above standard error bars indicate a significant difference among means at Type I error $=0.05$ (LSD test).

S. exigua [3,37]. The insects defend against the viral infection and replication with their potent immune system $[38,39]$. PM serves as the frontier physical barrier to deter viral infection of the midgut epithelium [40]. This explains the role of viral metalloprotease called 'enhancin' in degrading PM to enhance the pathogenicity of NPV [41]. In addition to PM, the insect midgut also plays a crucial role in fighting against the viral infection by expressing innate immune responses and damage repair machinery [42]. RNA interference, apoptosis, autophagy, and immune signal pathways such as JNK, JAK-STAT, and p38 MAPK are important insect defense machineries against viral infection $[43,44]$. Furthermore, several hydrolytic enzymes such as lipase, serine protease, and alkaline trypsin from the midgut of Bombyx mori have been found to exhibit remarkable antiviral activities [4547]. Upon SeMNPV infection, 124 putative innate immunity-related genes are differentially expressed in the larval midgut of S. exigua. They are divided into several groups, including pattern recognition proteins, signaling 
A
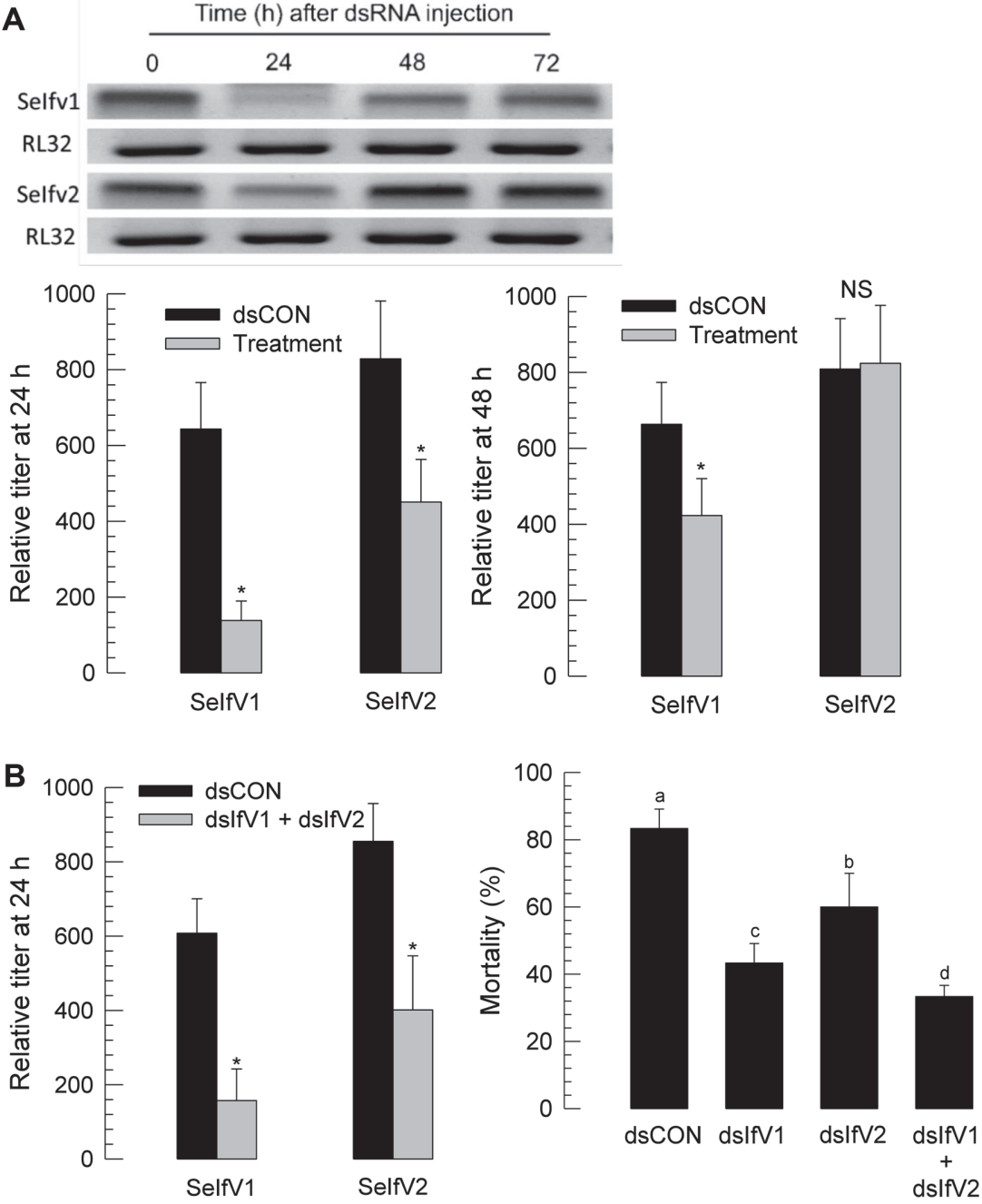

Fig. 6. RNAi treatment against SeIfV1 and SeIfV2. (A) RNAi efficiency was assessed by RT-qPCR. RL32 was used as a reference gene of RT-qPCR to normalize target gene expression level. Each treatment was replicated with independently prepared samples. (B) Effects of RNAi specific for SeIfV1 and SeIfV2 on survivability. Different letters above standard deviation bars indicate significant difference among means at Type I error $=0.05$ (LSD test).

pathways, signal modulation, antimicrobial peptides and detoxification [48].

Two SeIfV strains were detected in the laboratory colony S. exigua in the present study. These SeIfVs were pathologically associated with viral diseases because their specific RNAi treatment significantly rescued infected larvae. Iflaviruses can form non-enveloped, icosahedral particles containing a positive single-stranded RNA genome encoding one large polypeptide which is then post-translationally processed into structural viral coat proteins and nonstructural proteins associated with viral replication and protein processing [17]. IfV was initially found to be able to infect insects of economic importance such as honey bees and silkworms, causing diarrhea, developmental malformation, and death along with asymptomatic infection. Sacbrood disease is an example of a fatal IfV infection that prevents larva-to-pupal metamorphosis due to the Sacbrood virus (SBV) which fills in the exuvial space between larval and pupal cuticles in the pharate stage $[49,50]$. Deformed wing virus (DWV) is another example of a honey bee virus with symptomless infection. It can induce morphological abnormality in emerging adults, leading to crippled bees [51]. Colony collapse disease (CCD) was reported in honey bees in 2006. CCD bees are known to contain RNA viruses including DWV [52]. In addition, a flacherie symptom exhibiting diarrhea was observed in silkworms. The causative agent was IfV whose genome (9,650 nucleotides) was first sequenced [53]. There appears to be a positive virus-virus interaction between SeIfV and SeMNPV because IfV co-inoculation can consistently enhance the virulence of SeMNPV compared to larvae infected with SeMNPV alone [36]. An electron microscopy analysis revealed the presence of IfV virions inside SeMNPV OBs, suggesting the possible co-occlusion of both viruses [20]. Thus, physical protection such as resistance to UV radiation and high temperature may be offered by SeMNPV OBs, which could increase the infectivity of the IfV. This cooperative pathogenicity was observed in our current study. dsRNA treatment(s) specific to SeIfV1 or SeIfV2 effectively suppressed the IfV titers as shown in Fig. 6. Accordingly, the pathogenicity of the baculovirus was 
A

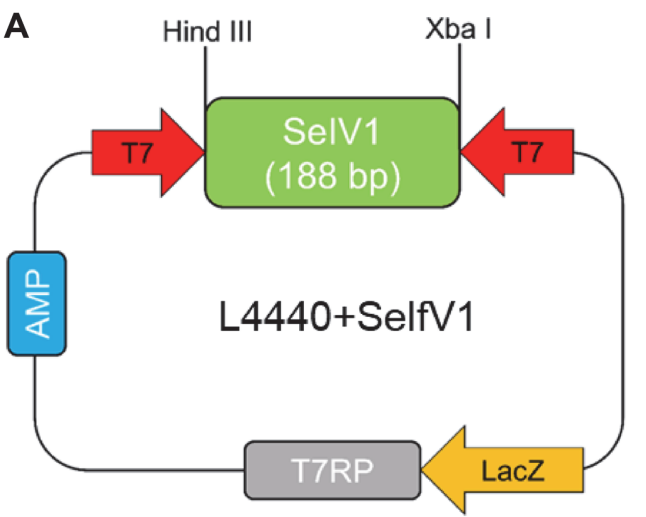

C

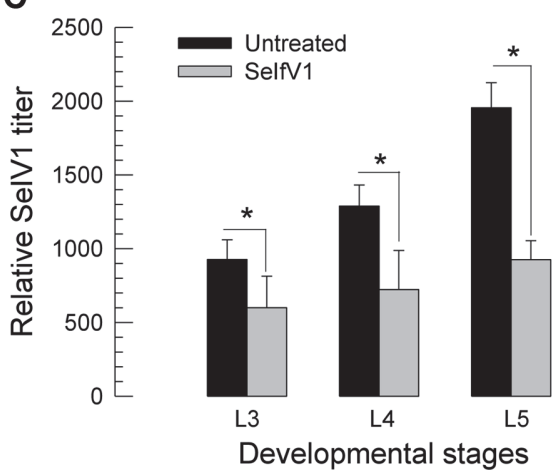

B

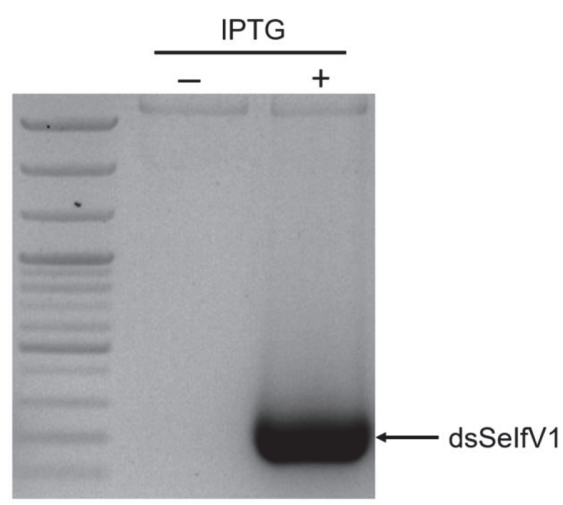

D

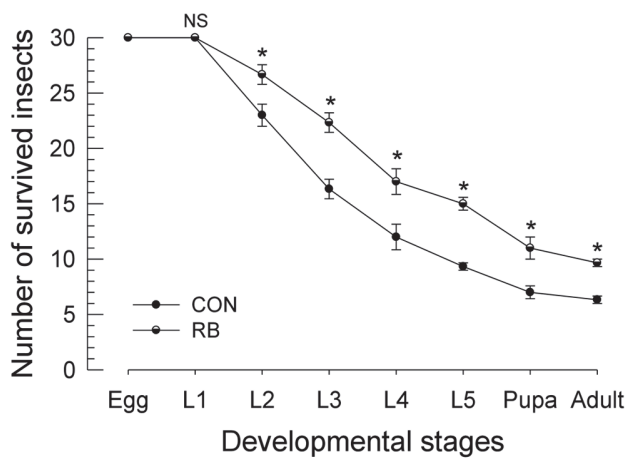

Fig. 7. Construction of recombinant $E$. coli expressing dsRNA specific to SeIfV1. (A) Cloning of a fragment of SeIfV1 (188 bp) into an expression vector of L4440 using HindIII and XbaI multiple cloning sites. After selecting transformed cells using ampicillin ('AMP') medium, T7 RNA polymerase ('T7 RP') was overexpressed by IPTG inducer on lactose promoter ('LacZ'). (B) Partial SeIfV1 RNA was transcribed by two opposite T7 promoters ('T7') and dsSeIfV1 production specifically in recombinant $E$. coli under IPTG induction was confirmed. (C) Effect of recombinant bacteria on SeIfV1 titer. Amounts of SeIfV 1 in L3, L4, and L5 stages were determined by qPCR. (D) Effect of recombinant bacteria (RB) on survivability. Asterisk $\left(^{*}\right.$ ) above standard deviation bars indicate significant difference among means at Type I error $=0.05$ (LSD test).

diminished. This decrease of mortality can be interpreted as iflavirus virulence or cooperative pathogenicity of iflavirsus with the baculovirus. However, our study demonstrated this cooperative pathogenicity of IfV with baculovirus because $\mathrm{NaOCl}$ treatment decreased SeMNPV titers without any change of IfV titers. This supports the enhanced pathogenicity of baculovirus due to IfV observed in other studies [19,21]. The observation of IfV in the envelop of baculovirus in an OB form [19] suggests a role of physical protection of IfV by baculovirus. This viral interaction may maintain their co-existence in S. exigua populations as observed in this current study.

Egg sterilization with $\mathrm{NaOCl}$ was effective in reducing SeMNPV, but not SeIfVs. Effective baculoviral epizootics occur via vertical and horizontal transmissions. These viral transmissions are possible because baculoviral OBs have been shown to persist for considerable periods of time outside their hosts if they are protected from UV such as by being in soil [54]. The sterilization in the current study might have removed external viral contamination of eggs through transovum transmission. However, it cannot completely eliminate the virus carried inside the egg via transovarial transmission [55]. Prevalence of covert infection plays a crucial role in maintaining viral persistence for controlling pest populations under their economic threshold levels in field crops [56]. Due to interest in using insect viruses as potential microbial control agents, baculoviruses that can kill their hosts relatively rapidly have attracted the greatest attention. On the other hand, it is advantageous for baculoviruses to keep their hosts alive and growing as long as possible because there is a negative correlation between the speed-to-kill and the quantity of virus progeny produce. SeIfV did not change the speed-to-kill, although it enhanced SeMNPV virulence, suggesting that they might be an ideal viral complex to control S. exigua in field conditions to induce viral epizootics.

Altogether, this study reports multiple viral infections by SeMNPV and SeIfV in a laboratory colony of S. exigua. These viral infections resulted in colony collapse of S. exigua. Surface sterilization of eggs partially prevented a vertical transmission of SeMNPV. RNAi suppressed SeIfV infection. This study also suggests that these two viruses are cooperative in pathogenicity and that their combined viral infection could be an ideal control tactic against $S$. exigua infesting field crops by inducing a serious viral epizootic. 


\section{Acknowledgments}

We thank Professor Yeon-Ho Je (Seoul National University, Seoul, Korea) for kindly providing Sf9 cells. This work was supported by a grant (2017R1A2133009815) of the National Research Foundation (NRF) and the Fourth BK21 Grant funded by the Ministry of Education, Republic of Korea.

\section{Conflict of Interests}

The authors have no financial conflicts of interest to declare.

\section{References}

1. Possee RD, Griffiths CM, Hitchman RB, Chambers A, Murguia-Meca F, Danquah J, et al. 2010. Baculoviruses: biology, replication and exploitation. In: Insect Virology (Eds. Asgari, S., Johnson, K.N.). pp. 35-57, Caister Academic Press, Norfolk, UK.

2. Jehle JA, Blissard GW, Bonning BC, Cory JS, Herniou EA, Rohrmann GF, et al. 2006. On the classification and nomenclature of baculoviruses: a proposal for revision. Arch. Virol. 151: 1257-1266.

3. Jiang Y, Deng F, Rayner S, Wang H and Hu Z. 2009. Evidence of a major role of GP64 in group I alphabaculovirus evolution. Virus Res. 142: $85-91$.

4. Zanotto PM, Kessing BD and Maruniak JE. 1993. Phylogenetic interrelationships among baculoviruses: evolutionary rates and host associations. J. Invertebr. Pathol. 62: 147-164.

5. Herniou EA, Olszewski JA, O’Reilly DR and Cory JS. 2004. Ancient coevolution of baculoviruses and their insect hosts. J. Virol. 78: 3244-3251.

6. Javed MA, Biswas S, Willis LG, Harris S, Pritchard C, van Oers MM, et al. 2017. Autographa californica multiple nucleopolyhedrovirus AC83 is a per os infectivity factor (PIF) protein required for occlusion-derived virus (ODV) and budded virus nucleocapsid assembly as well as assembly of the PIF complex in ODV envelopes. J. Virol. 91: 2115-2116.

7. Smagghe G, Pineda S, Carton B, Del Estal P, Budia F and Viñuela E. 2003. Toxicity and kinetics of methoxyfenozide in greenhouseselected Spodoptera exigua (Lepidoptera: Noctu-idae). Pest Manag. Sci. 59: 1203-1209.

8. Osorio A, Martínez AM, Schneider MI, Díaz O, Corrales JL, Avilés MC, et al. 2008. Monitoring of beet armyworm resistance to spinosad and methoxyfenozide in Mexico. Pest Manag. Sci. 64: 1001-1007.

9. Moscardi F. 1999. Assessment of the application of baculoviruses for control of Lepidoptera. Annu. Rev. Entomol. 44: 257-290

10. Sun XL and Peng H. 2007. Recent advances in biological control of pest Insects by using viruses in China. Virol. Sin. 22: 158-162.

11. Chen Y, Qi B, Zheng G, Zhang Y, Deng F, Wan F, et al. 2019. Identification and genomic sequence analysis of a new Spodoptera exigua multiple nucleopolyhedrovirus, SeMNPV-QD, isolated from Qingdao, China. J. Invertebr. Pathol. 160: 8-17.

12. ICTV. 2014. International Committee on Taxonomy of Viruses http://www.ictvonline.org/virusTaxonomy.asp.

13. Choi JY, Kim YS, Wang Y, Shin SW, Kim I, Tao XY, et al. 2012. Complete genome sequence of a novel picorna-like virus isolated from Spodoptera exigua. J. Asia Pac. Entomol. 15: 259-263.

14. Millán-Leiva A, Jakubowska AK, Ferré J and Herrero S. 2012. Genome sequence of SeIV-1, a novel virus from the Iflaviridae family infective to Spodoptera exigua. J. Invertebr. Pathol. 109: 127-133.

15. Himeno M, Onodera Kand Tanami Y. 1974. Properties of flacherie virus of the silkworm, Bombyx mori.J. Invertebr. Pathol. 23: 164-171.

16. Yue C, Schröder M, Gisder S and Genersch E. 2007. Vertical-transmission routes for deformed wing virus of honeybees (Apis mellifera). J. Gen. Virol. 88: 2329-2336.

17. van Oers MM. 2010. Genomics and biology of iflaviruses. In: Insect Virology, Asgari, S., Johnson, K. (Eds.). pp. 231-250. Caister Academic Press, Norfolk, UK.

18. Vail PV, Morris TJ, Collier SS and Mackey B. 1983. An RNA virus in Autographa californica nuclear polyhedrosis virus preparations: incidence and influence on baculovirus activity. J. Invertebr. Pathol. 41: 171-178.

19. Jakubowska AK, D’Angiolo M, González-Martínez RM, Millán-Leiva A, Carballo A, Murillo R, et al. 2014. Simultaneous occurrence of covert infections with small RNA viruses in the lepidopteran Spodoptera exigua. J. Invertebr. Pathol. 121: 56-63.

20. Jakubowska AK, Murillo R, Carballo A, Williams T, van Lent JW, Caballero P, et al. 2016. Iflavirus increases its infectivity and physical stability in association with baculovirus. PeerJ. 4: e1687.

21. Carballo A, Williams T, Murillo R and Caballero P. 2020. Iflavirus covert infection increases susceptibility to nucleopolyhedrovirus disease in Spodoptera exigua. Viruses 12: 509.

22. Szelei J, Woodring J, Goettel MS, Duke G, Jousset FX, Liu KY, et al. 2011. Susceptibility of North-American and European crickets to Acheta domesticus densovirus (AdDNV) and associated epizootics. J. Invertebr. Pathol. 106: 394-399.

23. Kariithi HM, van Oers MM, Vlak JM, Vreysen MJ, Parker AG and Abd-Alla AM. 2013. Virology, epidemiology and pathology of Glossina hytrosavirus, and its control prospects in laboratory colonies of the tsetse fly, Glossina pallidipes (Diptera; Glossinidae). Insects 4: 287-319.

24. Mordecai GJ, Brettell LE, Pachori P, Villalobos EM, Martin SJ, Jones IM, et al. 2016. Moku virus; a new iflavirus found in wasps, honey bees and Varroa. Sci. Rep. 6: 34983 .

25. Goh HG, Lee SG, Lee BP, Choi KM, Kim JH. 1990. Simple mass-rearing of beet armyworm, Spodoptera exigua (Hübner) (Lepidoptera: Noctuidae), on an artificial diet. Kor. J. Appl. Entomol. 29: 180-183.

26. Bustin SA, Benes V, Garson JA, Hellemans J, Huggett J, Kubista M, et al. 2009. The MIQE guidelines: minimum information for publication of quantitative real-time PCR experiments. Clin. Chem. 55: 611-622.

27. Livak KJ and Schmittgen TD. 2001. Analysis of relative gene expression data analysis using real-time quantitative PCR and the $2^{-\Delta \Delta C T}$ method. Methods 25: 402-408.

28. Choi JY, Woo SD, Je YH and Kang SK. 1999. Development of a novel expression vector system using Spodoptera exigua nucleopolyhedrovirus. Mol. Cells 9: 504-509.

29. Vatanparast M, Ahmed S, Herrero S and Kim Y. 2018. A non-venomous $\mathrm{sPLA}_{2}$ of a lepidopteran insect: Its physiological functions in development and immunity. Dev. Comp. Immunol. 89: 83-92.

30. Kim E, Park Y and Kim Y. 2015. A transformed bacterium expressing double-stranded RNA specific to integrin $\beta 1$ enhances Bt toxin efficacy against a polyphagous insect pest, Spodoptera exigua. PLoS One 10: e0132631.

31. SAS Institute Inc. 1989. SAS/STAT User's Guide. SAS Institute, Cary, NC.

32. Virto C, Navarro D, Tellez MM, Herrero S, Williams T, Murillo R, et al. 2014. Natural populations of Spodoptera exigua are infected by multiple viruses that are transmitted to their offspring. J. Invertebr. Pathol. 122: 22-27.

33. Sanekata T, Fukuda T, Miura T, Morino H, Lee C, Maeda K, et al. 2010. Evaluation of the antiviral activity of chlorine dioxide and sodium hypochlorite against feline calicivirus, human influenza virus, measles virus, canine distemper virus, human herpesvirus, human adenovirus, canine adenovirus and canine parvovirus. Biocontrol. Sci.15: 45-49.

34. Cory JS. 2010. The ecology of baculoviruses. In: Insect virology (Eds. Asgari, S., Johnson, K.), pp. 411-427. Caister Academic Press, Norfolk, UK. 
35. Murillo R, Hussey MS and Possee RD. 2011. Evidence for covert baculovirus infections in a Spodoptera exigua laboratory culture. J. Gen. Virol. 92: 1061-1070.

36. Carballo A, Murillo R, Jakubowska A, Herrero S, Williams, T and Caballero P. 2017. Co-infection with iflaviruses influences the insecticidal properties of Spodoptera exigua multiple nucleopolyhedrovirus occlusion bodies: Implications for the production and biosecurity of baculovirus insecticides. PLoS One 12: e0177301.

37. Guo HF, Fang JC, Wang JP, Zhong WF and Liu BS. 2007. Interaction of Xestia c-nigrum granulovirus with peritrophic matrix and Spodoptera litura nucleopolyhedrovirus in Spodoptera litura. J. Econ. Entomol. 100: 20-25.

38. Granados RR and Lawler KA. 1981. In vivo pathway of Autographa californica baculovirus invasion and infection. Virology 108: 297308.

39. Sabin LR, Zhou R, Gruber JJ, Lukinova N, Bambina S, Berman A, et al. 2009. Ars2 regulates both miRNA- and siRNA- dependent silencing and suppresses RNA virus infection in Drosophila. Cell. 138: 340-351.

40. Denecke S, Swevers L, Douris V and Vontas J. 2018. How do oral insecticidal compounds cross the insect midgut epithelium? Insect Biochem. Mol. Biol. 103: 22-35.

41. Toprak U, Harris S, Baldwin D, Theilmann D, Gillott C, Hegedus DD, et al. 2012. Role of enhancin in Mamestra configurata nucleopolyhedrovirus virulence: selective degradation of host peritrophic matrix proteins. J. Gen. Virol. 93: 744-753.

42. Wu K, Yang B, Huang WR, Dobens L, Song HS and Ling EJ. 2016. Gut immunity in Lepidopteran insects. Dev. Comp. Immunol. 64: 65-74.

43. Hoffmann JA. 2003. The immune response of Drosophila. Nature 426: 33-38.

44. Tanaka H, Ishibashi J, Fujita K, Nakajima Y, Sagisaka A, Tomimoto K, et al. 2008. A genome-wide analysis of genes and gene families involved in innate immunity of Bombyx mori. Insect Biochem. Mol. Biol. 38: 1087-1110.

45. Ponnuvel KM, Nakazawa H, Furukawa S, Asaoka A, Ishibashi J, Tanaka H, et al. 2003. A lipase isolated from the silkworm Bombyx mori shows antiviral activity against nucleopolyhedrovirus. J. Virol. 77: 10725-10729.

46. Nakazawa H, Tsuneishi E, Ponnuvel KM, Furukawa S, Asaoka A, Tanaka H, et al. 2004. Antiviral activity of a serine protease from the digestive juice of Bombyx mori larvae against nucleopolyhedrovirus. Virology 321: 154-162.

47. Ponnuvel KM, Nithya K, Sirigineedi S, Awasthi AK and Yamakawa M. 2012. In vitro antiviral activity of an alkaline trypsin from the digestive juice of Bombyx mori larvae against nucleopolyhedrovirus. Arch. Insect Biochem. Physiol. 81: 90-104.

48. Chen Y, Guo L, Wan N, Ji X, Zhang H and Jiang J. 2020. Transcriptomic analysis of the interactions between the Spodoptera exigua midgut and nucleopolyhedrovirus. Pestic. Biochem. Physiol. 163: 241-253.

49. White G. 1913. Sacbrood, a disease of bees. US Dept. Agr. Bur. Entomol. Circ. 169.

50. Bradbear N. 1988. World distribution of major honey bee diseases and pests. Bee World 69: 15-39.

51. Yue C and Genersch E. 2005. RT-PCR analysis of Deformed wing virus in honeybees (Apis mellifera) and mites (Varroa destructor). J. Gen. Virol. 86: 3419-3424.

52. Johnson RM, Evans JD, Robinson GE and Berenbaum MR. 2009. Changes in transcript abundance relating to colony collapse disorder in honey bees (Apis mellifera). Proc. Natl. Acad. Sci. USA 106: 14790-14795.

53. Isawa H, Asano S, Sahara K, Iizuka T and Bando H. 1998. Analysis of genetic information of an insect picorna-like virus, infectious flacherie virus of silkworm: evidence for evolutionary relationships among insect, mammalian and plant picorna(-like) viruses. Arch. Virol. 143: 127-143.

54. Fuxa JR. 2004. Ecology of insect nucleopolyhedrosises. Agr. Ecosyst. Environ. 103: 27-43.

55. Kukan B. 1999. Vertical transmission of nucleopolyhedrosis in insects. J. Invertebr. Pathol. 74: 103-111.

56. Dwyer G, Dushof J and Yee SH. 2004. The combined effects of pathogens and predators on insect outbreaks. Nature 430: $341-345$. 